\title{
Erratum to: Local distal radius bone graft versus iliac crest bone graft for scaphoid nonunion: a comparative study
}

Tarun Goyal • Sukesh Rao Sankineani •

Sujit K. Tripathy

Published online: 3 November 2012

(C) Istituti Ortopedici Rizzoli 2012

Erratum to: Musculoskelet Surg

DOI 10.1007/s12306-012-0219-y

Unfortunately, the online published article has been published with the incorrect author group.

The correct author group should be as given below:

Tarun Goyal · Sukesh Rao Sankineani - Sujit K. Tripathy

The online version of the original article can be found under doi:10.1007/s12306-012-0219-y.

T. Goyal $(\bowtie) \cdot$ S. R. Sankineani · S. K. Tripathy

Department of Orthopaedics,

All India Institute of Medical Sciences, New Delhi, India

e-mail: goyal.tarun@gmail.com 